This item was submitted to Loughborough's Research Repository by the author.

Items in Figshare are protected by copyright, with all rights reserved, unless otherwise indicated.

\title{
Scanning acoustic microscopy investigation of engineered flip-chip
} delamination

PLEASE CITE THE PUBLISHED VERSION

PUBLISHER

(c) IEEE

LICENCE

CC BY-NC-ND 4.0

\section{REPOSITORY RECORD}

Hutt, David A., David C. Whalley, D. Patrick Webb, K.C. Hung, C.W. Tang, Paul P. Conway, and U.C. Chan. 2019. "Scanning Acoustic Microscopy Investigation of Engineered Flip-chip Delamination". figshare.

https://hdl.handle.net/2134/3929. 
This item was submitted to Loughborough's Institutional Repository (https://dspace.lboro.ac.uk/) by the author and is made available under the following Creative Commons Licence conditions.

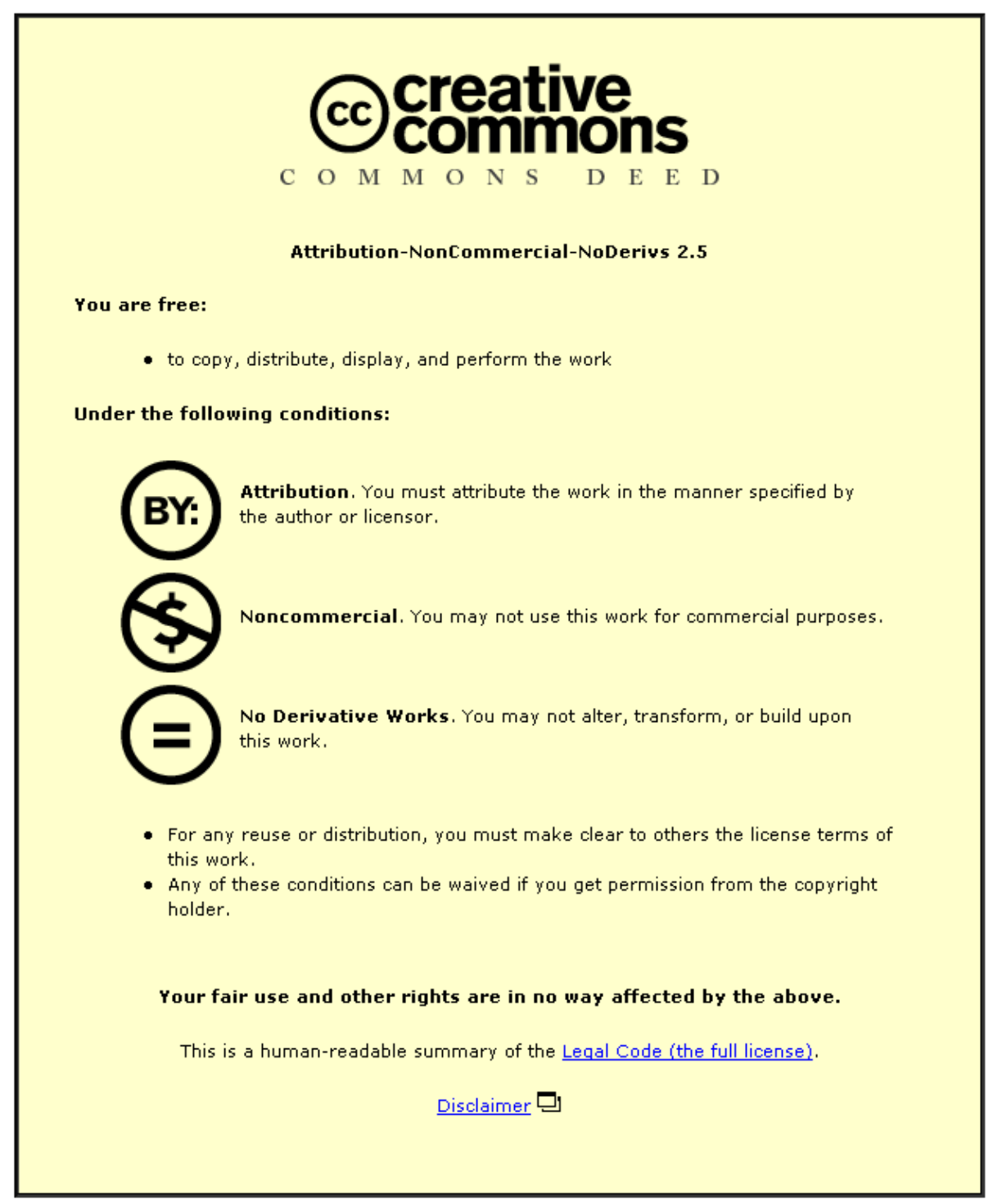

For the full text of this licence, please go to: http://creativecommons.org/licenses/by-nc-nd/2.5/ 


\title{
Scanning Acoustic Microscopy Investigation of Engineered Flip-chip Delamination
}

\author{
D.A. Hutt, D.P. Webb, K.C. Hung*, C.W. Tang*, \\ P.P. Conway, D.C. Whalley and Y.C. Chan* \\ Department of Manufacturing Engineering, Loughborough University, \\ Loughborough, LE11 3TU, UK. \\ *EPA Centre, City University of Hong Kong, Department of Electronic Engineering, \\ 83 Tat Chee Avenue, Kowloon, Hong Kong, PRC.
}

\begin{abstract}
The rapid uptake of flip-chip technology within the electronics industry, is placing the reliability of such assemblies under increasing scrutiny. A key feature of the assembly process is the application of underfill to reinforce the attachment of the die to the printed circuit board. This has been identified in numerous studies as one of the major ways in which the reliability of the devices can be improved, by mitigating the coefficient of thermal expansion mismatch between chip and board. However, in order for the underfill to be effective in coupling the die to the circuit board, its adhesion to the passivation layer of the die and the solder mask layer on the PCB must be maximised. There is a growing body of literature that indicates that poor adhesion at either interface (delamination) as a result of contamination can result in premature failure of the assembly through stress fracture of the solder joints.

In order to investigate further the effect of delamination on the reliability of flip-chip assemblies, surface chemistry has been used to control the adhesion of the underfill to the die passivation. This paper reports how modification of the die surface by the application of a low surface energy coating, which prevents the strong adhesion of the underfill, has enabled the selective delamination of the device at the chip-to-underfill interface. Using scanning acoustic microscopy (SAM) the effectiveness of this treatment in creating controlled delamination before and after thermal cycling has been monitored. The ability to engineer delamination, can enable experimental studies of the mechanics of flip chip assembly failure, which complement current finite element modelling work.
\end{abstract}

\section{Introduction}

With the increasing utilisation of flip-chip technology in electronics manufacture, the requirement for high speed assembly processes is becoming more important. One part of the assembly process that has attracted considerable interest as an area in which improvements can be made is the dispensing and curing of the underfill. The application of underfill is essential to maintaining the reliability of flip-chip assemblies by reducing the impact of the coefficient of thermal expansion (CTE) mismatch between the chip and the board which

0-7803-6482-1/00/\$10.00 @2000 IEEE otherwise would lead to rapid fatigue failure of the solder joints during operation.

The drive to increase the throughput of flip-chip assembly lines has led to extensive research in the areas of pre-deposited underfill, fluxing (no-flow) underfill, snapcure underfill and fast flow underfill. The introduction of these new materials has required extensive investigation of their ability to maintain the reliability of the assemblies, which is traditionally monitored through thermal cycling studies. The key underfill properties that determine its effectiveness for reliability enhancement are its modulus of elasticity, CTE and its adhesion to the PCB, solder ball and die surfaces. Through extensive modelling studies and experimental trials it has been shown that the CTE of the material should be between that of the PCB and the die to ensure the maximum lifetime of the device. However, the integrity of the underfill to chip or underfill to PCB interfaces is also seen as essential to enable the underfill to provide effective coupling of the chip to the board. Through reliability studies of flip-chip assemblies there is increasing evidence that failure at these interfaces (delamination) leads to early failure of the device. The origins of delamination are varied, but it is often attributed to surface contamination due, for example, to flux residues. The non-destructive technique of scanning acoustic microscopy (SAM) is gaining extensive use for quality control in the electronic packaging industry and has been applied by researchers to investigate flip-chip packages. The technique is able to identify delamination in flip-chip devices due to the strong reflection of sound energy at internal interfaces between the package materials and air or vacuurn.

In order to enhance the adhesion of the underfill to the chip surface, new underfill material formulations have been examined [e.g. 1,2]. All of these rely on the formation of a strong chemical bond between the die passivation and the underfill epoxy resin through the introduction of chemical species that make borids directly with both materials. The work of C.P. Wong [2] is a good example of this: he has incorporated silane species into the underfill material that have a chemical head group that bonds selectively to the passivation of the die and a tail group that interacts strongly with the epoxy species in the adhesive. An example of this is shown in figure 1a. The use of silane materials in this way, is reminiscent of the formation of self-assembled monolayers which have received 
considerable interest in recent years. Figure $1 \mathrm{~b}$ shows an example of the formation of a self-assembled monolayer of octadecyltrichlorosilane (OTS) on a $\mathrm{SiO}_{2}$ surface. In this example, the monolayer would be formed by immersing the sample that has a thin native layer of $\mathrm{SiO}_{2}$, into a dilute solution of OTS in a solvent. The OTS molecules adsorb onto the material surface by forming strong chemical bonds between the silane species and the silica surface. The long carbon chain backbones then align themselves away from the surface, maximising the van der Waals interactions between them and exposing the tail group, in this case $\mathrm{CH}_{3}$, at the surface. It is the ease with which surfaces with different chemical properties can be prepared by adsorbing molecules with different chemical species in the tail group that has generated interest in these materials.

\section{a)}

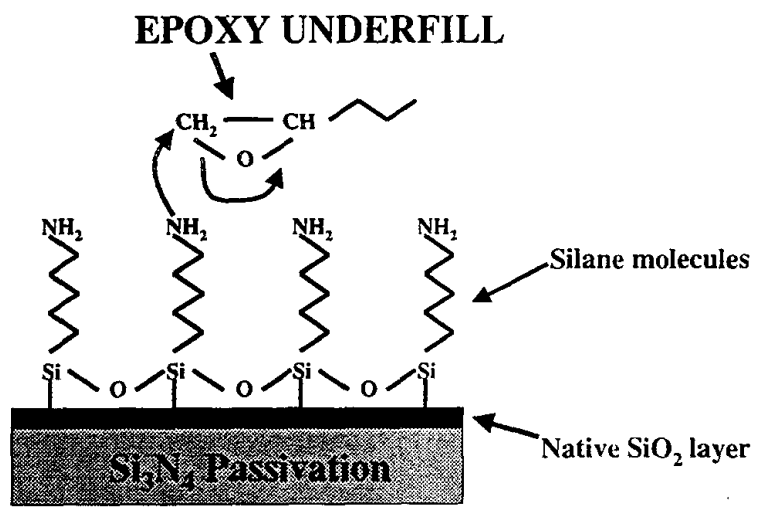

b)
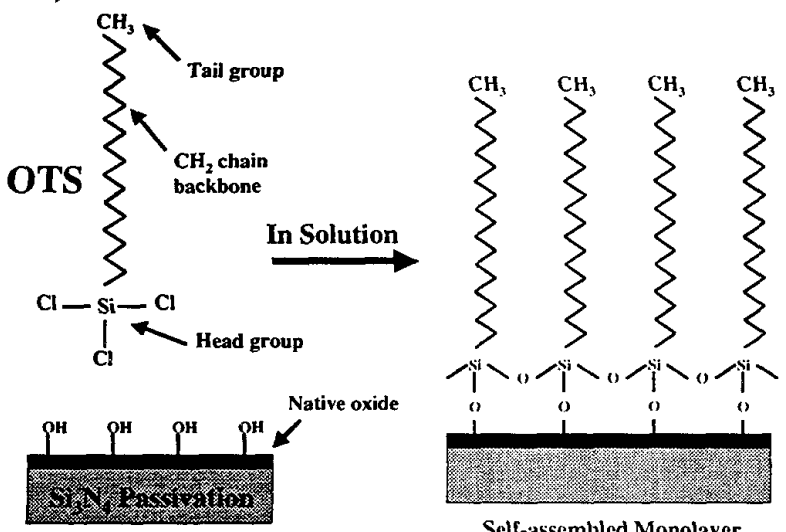

Figure 1: a) mechanism of adhesion promotion using silane additives in underfill; b) formation of a selfassembled monolayer of octadecyltrichlorosilane (OTS) on silicon nitride.

In the preliminary experiments reported here, delamination in flip-chip assemblies has been engineered through the deliberate minimisation of the adhesion between the die and the underfill. To achieve this. selfassembled monolayers of OTS on solder bumped die were

0-7803-6482-1/00/\$10.00 @2000 IEEE prepared as shown in figure $1 \mathrm{~b}$ to produce a low energy die surface composed of methyl $\left(\mathrm{CH}_{3}\right)$ species that would not bond covalently to the underfill. The aim of these experiments was to develop a tool for the understanding of delamination mechanisms and their effects on package reliability, and to use scanning acoustic microscopy to monitor the development of delamination during thermal cycling. This engineered delamination of flip-chip assemblies will in the future enable the validation of the results of computer simulations of device reliability. In addition, these preliminary experiments could lead to further studies where selected areas of the die are delaminated through the formation of patterned adhesion inhibitor layers, leading to a greater understanding of the mechanisms of device failure and the critical areas where adhesion should be maximised.

\section{Experimental}

As these were trial experiments, only two boards were assembled, each populated with 9 die. The first board (board 1) used a mixture of assembly techniques, including fluxing underfill, and presented some interesting preliminary results which were further investigated by the assembly of a second board (board 2) using a more limited range of technologies. The following sections describe the test devices used in this study and the assembly techniques employed. All wafer bumping and board assembly operations were performed in the UK, while thermal cycling and SAM analysis were conducted in Hong Kong. There was therefore a transportation operation between assembly and testing and the effect of this on the assemblies will be discussed further.

\section{Test Devices}

For these trials, $6 \mathrm{~mm} \times 6 \mathrm{~mm}$ test chips were used which included a daisy chain test structure of $75 \mu \mathrm{m}$ diameter Al bondpads at 300 and $225 \mu \mathrm{m}$ pitch. Bumping of the die was carried out on a wafer scale starting with the plating of an electroless nickel under bump metallisation ( $6 \mu \mathrm{m}$ thick) together with a gold flash. Following this, solder paste was printed and reflowed to produce solder bumps around $70 \mu \mathrm{m}$ high. Further details of the electroless nickel bumping process can be found elsewhere [3]. After bumping, the wafer was cleaned to remove flux residues before being diced into individual chips.

The printed circuit boards used for these studies were FR5 material with $25 \mu \mathrm{m}$ thick copper tracks and pads which were finished with electroless nickel and immersion gold. The nine electrically testable sites on the board matched the daisy chain configuration of the die and were divided into three groups based on the pad geometry and the method used to define the solderable area. Table 1 lists the range of sites available on the boards and figure 2 shows an image of one of the microvia in pad sites (no.s 69). The pads for sites 1-3 consisted of straight tracks with no solder mask, while sites 4 and 5 used a carefully applied solder mask to define a small wettable area on the track surface for joint formation. The microvia in pad sites did 2000 IEEE/CPMT Int'I Electronics Manufacturing Technology Symposium 
not use solder mask to define the solder wettable area as there was no exposed track along which the solder could run. Each site had an array of daisy chained pads around the periphery of the die that enabled the majority of the joints to be tested for continuity by one resistance measurement. These can be seen as the square array in the centre of figure 2. Further test points were provided running from each side of the die to allow failed joints to be located. In addition, eight larger test points were provided around the site to enable the four point measurement of two resistor structures on the die surface. These test pads can be seen clearly in figure 2 to the top and bottom of the bond site.

Table 1: PCB site type and dimensions

\begin{tabular}{||l|l|l||}
\hline Site No.s & Pad Type & Pad / track width \\
\hline $1-3$ & Bare track & $110 \mu \mathrm{m}$ wide \\
\hline $4-5$ & Solder mask defined & $110 \mu \mathrm{m}$ diameter \\
\hline $6-9$ & Microvia in round pad & $140 \mu \mathrm{m}$ diameter \\
\hline
\end{tabular}

\section{Application of Low Surface Energy Coating to Die}

The passivation on the die was $\mathrm{Si}_{3} \mathrm{~N}_{4}$, which has been shown [4] to possess a native $\mathrm{SiO}_{2}$ layer onto which

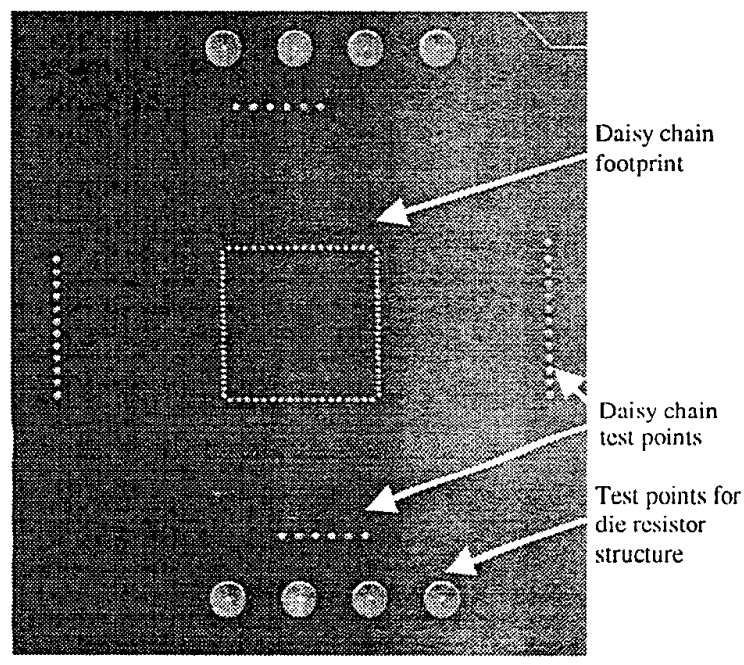

Figure 2: Site number 9 on PCB showing microvia in pad connections (central square). Small arrays of pads around the outside are for probing of daisy chain individual joints and large pads are for probing of die resistor structures.

silane species can adsorb. Octadecyltrichlorosilane (OTS) coatings were applied to the die using a traditional procedure for the formation of self-assembled monolayers [5]. This involved immersing the individual solder bumped die into a dilute solution of octadecyltrichlorosilane in cyclohexane $(\sim 10 \mathrm{mM}$ concentration) for between 1 and $1.5 \mathrm{hrs}$ followed by rinsing with cyclohexane and iso-propyl alcohol and then drying.

\section{Board Assembly and Underfilling}

Die were assembled onto the sites on the boards in pairs i.e. a coated die next to an uncoated die on the same type of site, so that direct comparison between them could be made. Table 2 lists the assembly configurations used for these trials. Die were assembled to the board by applying flux to the die, followed by die placement. Flux was applied by using a doctor blade to produce a thin layer of tacky flux on a metal plate into which the die were placed face down. For the die used on board 2 this provided a small quantity of flux on each of the solder balls that was sufficient to form good joints during reflow, however for the die used on board 1, some additional flux became attached to the surface of the chip which remained in the assembly after reflow.

Following reflow, the die assembled onto board 1 using the no-flow underfill were found to have moved and were not conducting. Further detailed investigation of these devices was therefore not pursued. For the die assembled using tacky flux a much higher assembly yield was achieved and these devices were underfilled without any cleaning treatment applied. A commercially available underfill was used for all assemblies and was dispensed manually along two sides (L shape) of the die, which was heated to $80-90^{\circ} \mathrm{C}$. Material was continually added until it was seen to flow out of the other two sides of the assembly, after which, additional underfill was dispensed to form fillets all around the device. The underfill was then postcured in an oven at $150^{\circ} \mathrm{C}$ for 30 mins.

Table 2: Board assembly parameters

\begin{tabular}{|l|l|l|l|l||}
\hline & \multicolumn{2}{|c|}{ BOARD 1 } & \multicolumn{2}{c|}{ BOARD 2 } \\
\hline Site & $\begin{array}{l}\text { Coated / } \\
\text { Uncoated } \\
\text { Die }\end{array}$ & $\begin{array}{l}\text { Assembly } \\
\text { Technique }\end{array}$ & $\begin{array}{l}\text { Coated / } \\
\text { Uncoated } \\
\text { Die }\end{array}$ & $\begin{array}{l}\text { Assembly } \\
\text { Technique }\end{array}$ \\
\hline 1 & & Tacky flux & Coated & Tacky flux \\
\hline 2 & & Tacky flux & Coated & Tacky flux \\
\hline 3 & & No-flow & & Tacky flux \\
\hline 4 & Coated & Tacky flux & Coated & Tacky flux \\
\hline 5 & Coated & No-flow & & Tacky flux \\
\hline 6 & & Tacky flux & & Tacky flux \\
\hline 7 & Coated & Tacky flux & Coated & Tacky flux \\
\hline 8 & & No-flow & Coated & Tacky flux \\
\hline 9 & Coated & No-flow & & Tacky flux \\
\hline
\end{tabular}

\section{Thermal cycling}

Thermal cycling of the assemblies was conducted using an air-air system. The profile used was $-40^{\circ} \mathrm{C}$ to $+125^{\circ} \mathrm{C}$ with a hold at each temperature of $30 \mathrm{mins}$ for board 1, and a hold of 15 mins for board 2. Board 1 was exposed to 111 thermal cycles, while board 2 received 430 cycles in the time available. The different hold times and limited number of thermal cycles for the two boards were used for reasons of time pressure on the cycling chamber. 


\section{Scanning Acoustic Microscopy (SAM)}

The scanning acoustic microscope used was a Sonix Inc. system [6]. For analysis, the sample is immersed in water and a sonic transducer emitting sound wave pulses is scanned over the surface by a highly accurate translation stage. Sound energy is reflected by internal interfaces in the sample and detected by the same sonic transducer. The depth at which the reflection occurs may be estimated from the time at which the reflected sound pulse is received. Total reflection of the sound pulse occurs at the interface between solid materials and air or vacuum, for example at a void or delamination. An image is built up from the scan by gating the reflection signal from the transducer to cover the layer or layers of interest in the device. The magnitude of the largest reflection between the gates is mapped to a greyscale value to form a pixel of the image. Because total reflection of the sound pulse occurs at the interface between solid materials and air or vacuum, voids and delaminations usually cause the largest reflected signal and hence appear white within the image. In this work a transducer frequency of $230 \mathrm{MHz}$ was used and the gates set to cover both the chip to underfill and the underfill to board interfaces.

\section{Laser Profilometer Measurements}

In order to measure the extent of curvature of the die at various stages of assembly, a laser profilometer system was used. This consisted of an infra red laser and focus detector that was mounted in a frame above an $X-Y$ translation table. To record data from the back surface of the die, the PCB was mounted on the table and scanned beneath the laser, the reflection of which was used to build up an image of the sample height as a function of the $X-Y$ position. The profiles shown in this paper were extracted from complete scans of the back surfaces of the die and display the curvature across the die width from left to right.

\section{Results}

\section{Die Curvature Measurements}

The difference in the coefficients of thermal expansion of the silicon die and the FR5 PCB, together with the high temperature cure of the underfill material, means that the die attached to the $\mathrm{PCB}$ are expected to be curved following assembly [7]. Figure 3 shows laser profiles obtained from the back surfaces of a number of devices at various stages of the assembly process. Figure $3 \mathrm{a}$ shows a profile obtained from a bare die before assembly onto the circuit board. This profile shows no curvature, as expected, and forms a control from which the other assemblies can be judged. Figure $3 b$ shows a profile obtained from a die that had just been reflowed onto the PCB and allowed to cool to room temperature. Again there is no curvature observable in the data. This is unexpected, as at $183^{\circ} \mathrm{C}$ when the solder solidifies, the die should be in a stress free condition (i.e. planar) and cooling to room temperature is likely to induce curvature as the board contracts more than the silicon. The absence of any curvature in the profile of figure $3 b$ even only 15 minutes after the reflow process indicates that the solder joints are

0-7803-6482-1/00/\$10.00 @2000 IEEE able to relax (creep) sufficiently to relieve the stress and remove the curvature from the assembly.

a)

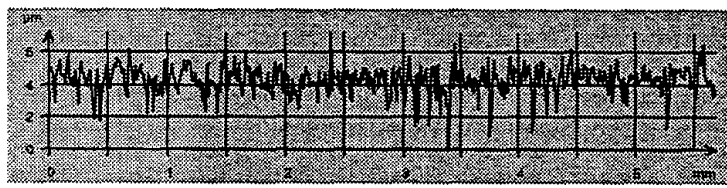

b)

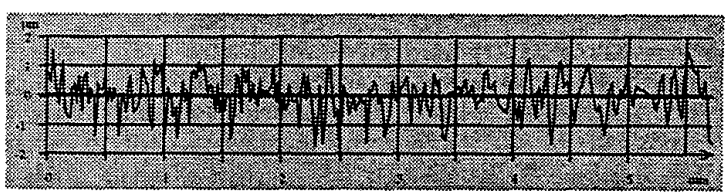

c)

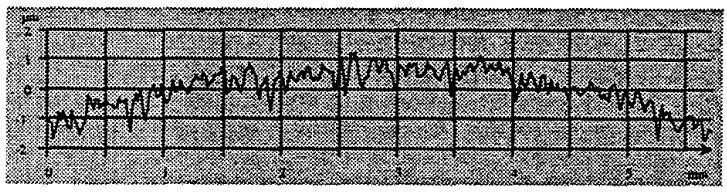

d)

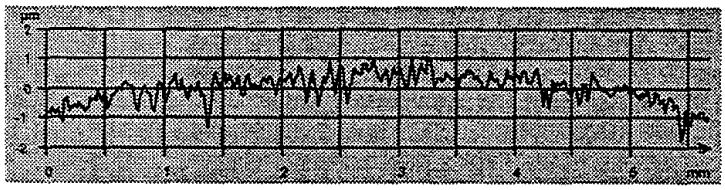

Figure 3: Laser profilometer data obtained from die at different stages of assembly. a) bare die not attached to PCB; b) after die reflowed onto PCB; c) after underfill dispense and cure of assembly (uncoated die); d) after underfill dispense and cure of assembly (OTS coated die).

For die with no coating, following underfill dispensing and then post-curing of the devices, the die were found to have a significant degree of curvature as shown in the profile of figure $3 \mathrm{c}$. This indicated that the edges of the die were deflected by around $2-2.5 \mu \mathrm{m}$ compared to the centre of the die. This result was found for several assemblies produced in this way using the conventional underfill material and this agrees with model calculations made by Wheeler and Bailey [8] based on these devices. These results indicate that the solidification of the underfill during the post-cure at $150^{\circ} \mathrm{C}$, locks the die to the PCB so that during cooling to room temperature, the greater contraction of the PCB compared to the silicon chip causes extensive bowing of the latter.

For the die treated with OTS (Figure 3d), a similar curvature profile was obtained as for the uncoated die (Figure 3c). However, closer inspection of the data revealed that the deflection of the OTS coated die was only $1.5 \mu \mathrm{m}$ at the edge of the chip with respect to the centre. This would appear to indicate that the application of the coating reduces the interaction of the underfill with the die surface, leading to less curvature on cooling.

Electrical Testing of Assemblies 2000 [EEE/CPMT Int'] Electronics Manufacturing Technology Symposium 
Following assembly, board 2 was electrically tested to measure the resistance of the daisy chain connections around the whole die and the shorter four point resistance chains situated on either side of the assemblies. All daisy chains of the uncoated die were conducting

Table 3: Number of thermal cycles to electrical failure for die assembled onto board 2

\begin{tabular}{||l|l|l|l||}
\hline $\begin{array}{l}\text { Site } \\
\text { No. }\end{array}$ & Die Type & Full daisy chain & $\begin{array}{l}\text { Four point } \\
\text { edge test sites }\end{array}$ \\
\hline 1 & OTS coated & Transportation & $<117$ cycles \\
\hline 2 & OTS coated & Transportation & $<117$ cycles \\
\hline 3 & Uncoated & $>430$ cycles & $>430$ cycles \\
\hline 4 & OTS coated & Transportation & $<220$ cycles \\
\hline 5 & Uncoated & $>430$ cycles & $>430$ cycles \\
\hline 6 & Uncoated & $>430$ cycles & $>430$ cycles \\
\hline 7 & OTS coated & Transportation & $<220$ cycles \\
\hline 8 & OTS coated & Transportation & $<220$ cycles \\
\hline 9 & Uncoated & $>430$ cycles & $>430$ cycles \\
\hline
\end{tabular}

immediately after assembly and after underfilling. However, the OTS coated die generally formed higher resistance daisy chains compared to the uncoated chips.

a)

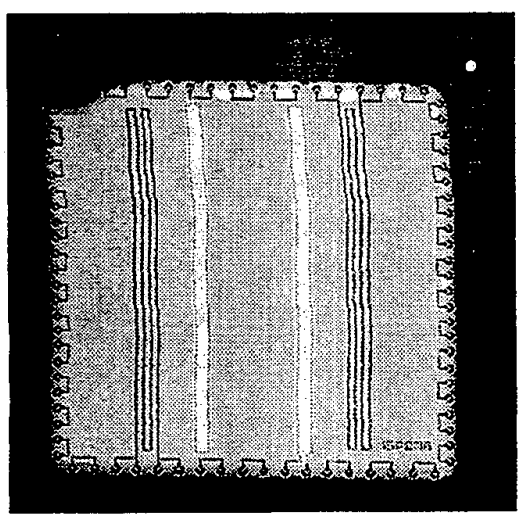

b)

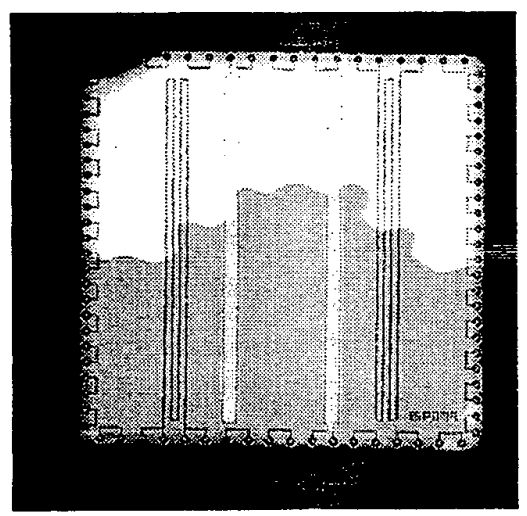

Figure 4: SAM images of OTS coated die assembled onto board 1: a) before thermal cycling; b) after 111 thermal cycles.
Subsequent cross-section analysis showed that the majority of solder joints were well formed, but for the OTS coated die, one or two dry joints had occurred leading to only a pressure contact between the solder and the copper track.

After transportation to Hong Kong, the full daisy chains of the assemblies formed from the OTS coated die had all failed, presumably due to the separation of these dry joints. This left only the shorter four point resistance chains operational for testing which were used to monitor the effects of thermal cycling on the devices.

Resistance measurements were performed at room temperature after 117,220 and 430 cycles. Table 3 summarises the results of the electrical tests as a function of the thermal cycling for board 2. From these results it can be seen that two of the die with the OTS coating had failed before 117 cycles, while the remaining die with the OTS coating failed before 220 cycles. In contrast, die without the OTS coating were all still conducting with little change in joint resistance after 430 cycles.

\section{Scanning Acoustic Microscopy Measurements}

SAM measurements were performed on the two assembled boards before and after thermal cycling. Figure 4 shows the SAM images obtained from one of the two OTS coated die assembled onto board 1 using tacky flux. Before cycling, this die showed some delamination in the vicinity of the joints across the top of the die. However, following 111 thermal cycles, this device displayed severe delamination in the SAM image and some delamination was also found for the other OTS coated die. For die that were uncoated, no delamination was observed following this thermal cycling regime. The substantial delamination observed for the coated die was consistent with our expectations based on the poor adhesion of underfill to chip surface induced by the OTS coating. The poor adhesion was further demonstrated by the complete detachment of the die from the PCB during handling of the assembly for cross-section analysis.

In order to repeat the experiment, board 2 was prepared and assembled, this time successfully avoiding tacky flux reaching the die passivation. As described above, the OTS coated die assembled onto this board all failed the daisy chain electrical continuity test following transportation to Hong Kong, and following limited thermal cycling, all the remaining electrical connections on the die became open circuit. Figure 5 shows representative SAM images obtained from an OTS coated die assembled onto board 2 before and after thermal cycling. In contrast to the coated die assembled onto board 1 , none of the OTS coated die on board 2 showed any delamination even after 430 thermal cycles (the maximum time allowed for these trials). 
a)

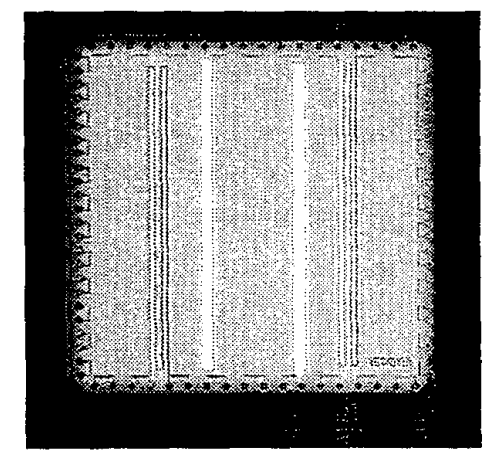

b)

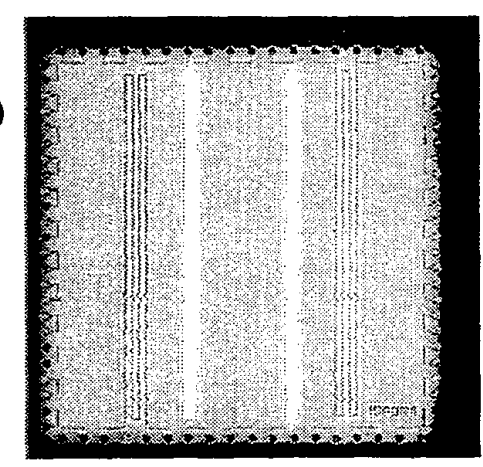

Figure 5: SAM images of OTS coated die assembled onto board 2: a) before thermal cycling; b) after 430 thermal cycles.

\section{Cross-section Analysis}

Following thermal cycling and SAM examination, the boards were returned to the UK for further die curvature and cross-section analysis. Laser profilometer measurements of the assemblies prepared without the OTS coating still indicated significant curvature of the back face of the die comparable to that observed before thermal cycling. This would indicate the die were still firmly attached to the board supporting the conclusion from the SAM and electrical measurements. A cross-section of the die bonded to site 5 of board 2 is shown in figure 6 a. This shows clearly the integrity of the solder joint between the circuit board and the electroless nickel bump on the die as expected from the electrical continuity of the daisy chain connections.

For the die that had been coated with OTS and reflowed onto site 4 of board 2 (matching site to number 5 described above), a very different picture emerged of the die condition. The laser profilometer measurements indicated no curvature of the die at all after 430 thermal cycles and the cross-section (figures $6 \mathrm{~b}$ and $6 \mathrm{c}$ ) showed clearly a substantial separation between the die and the underfill. The presence of a large separation between die and underfill in the cross-section is unexpected as the SAM images did not indicate any delamination. At present, it has not been possible to determine whether this separation occurred as a result of sample preparation for cross-section analysis or damage in transit of the board from Hong Kong to the UK. The absence of any die curvature after receipt of

$0-7803-6482-1 / 00 / \$ 10.00 \bigcirc 2000$ IEEE the board in the UK could indicate that this separation did take place in transit leading to the die reverting to its planar, stress free condition. The nature of the joint failure observable in the cross-sections of figures $6 \mathrm{~b}$ and $6 \mathrm{c}$ is interesting, as a mixed mode of failure appears to have taken place. In some joints, fracture of the solder near the electroless nickel bump surface can be observed, however in others, the electroless nickel bump has been pulled from the Al bondpad. This later failure mode is rarely observed in normal assemblies and it is unclear whether these fractures were the cause of the electrical failures or whether they have been induced later on by the substantial separation of the die from the underfill. Remember the SAM images did not indicate delamination even though the joints had failed. The surrounding of the solder ball by the underfill during separation could have produced a solder ball pull effect which resulted in the fracture of the electroless nickel - aluminium interface. Alternatively, the weak adhesion of the underfill to the die surface could have led to a shearing action of the cured adhesive across the die surface during thermal cycling, again resulting in the fracture at the NiP-Al interface.

\section{Die Pull-off Testing}

For the die that had been coated with OTS, the complete non-adhesion of the underfill to the chip surface was further demonstrated by pulling off the die from the boards. For the coated samples this was extremely easy and an example of the result obtained from this is shown in figure 7. This shows a die that has been pulled off the board leaving behind the underfill with an impression of the chip in it. Analysis of the solder joints showed that these had successfully formed during assembly, but had been fractured either before or during the pull-off test. The clean surface of the die and the smooth underfill left behind indicated that there was no adhesion between the two surfaces. There was no evidence of any voids. 
a)

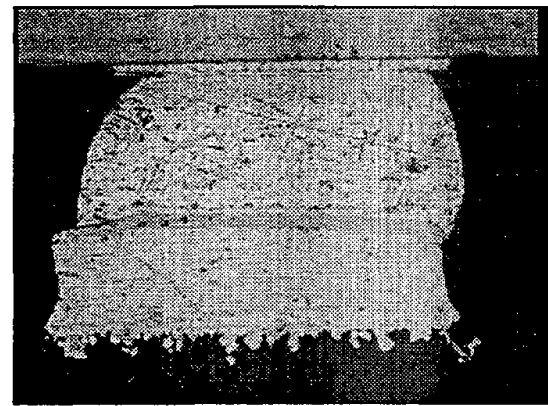

b)

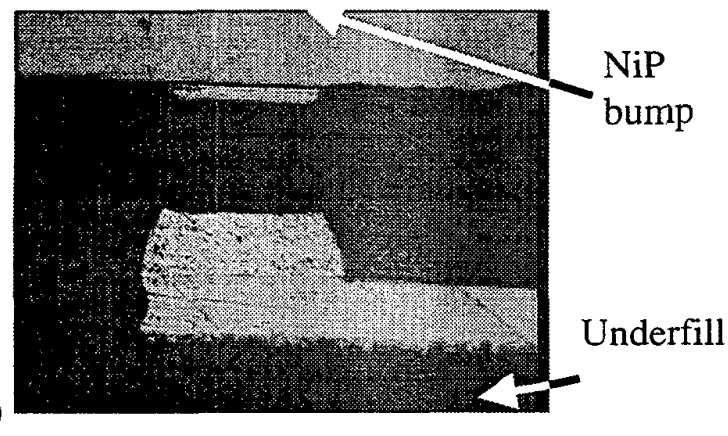

c)

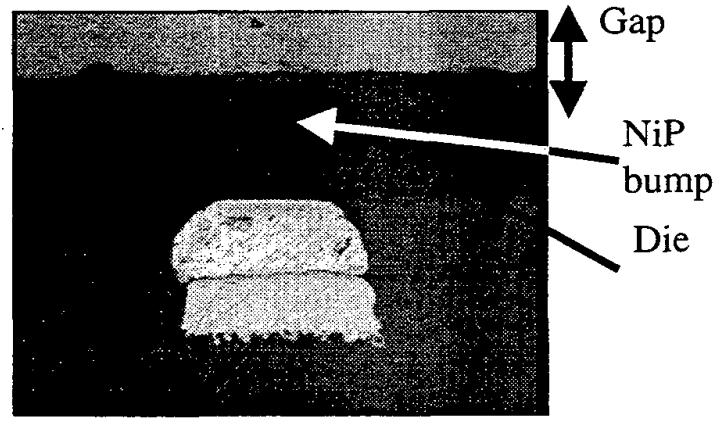

Figure 6: Cross-sections of assemblies on board 2 after 430 thermal cycles. a) site 5 , no coating on die surface; b) site 4, OTS coating on die, fracture at electroless nickel solder interface; c) site 4 , OTS coating on die, fracture at e electroless nickel - aluminium interface.

\section{Discussion}

The rapid electrical failure during thermal cycling of die coated with OTS is in line with expectations regarding the delamination of the underfill - die interface. The extensive delamination observed in the SAM images of the die assembled onto board 1 is to be expected considering the poor adhesion of chip to underfill engineered into the assembly. However, the intriguing issue is the lack of evidence of delamination observable in the SAM images of the OTS coated die on board 2, despite the complete failure of the die after 220 thermal cycles. Clearly, at this stage there was no appreciable adhesion between the die and the underfill as indicated by the ease with which the die could be removed from the board surface.

The answer to this contradiction between the two boards may lie in the different accuracy of the flux application. In order for SAM to observe delamination, a separation must occur between the die and the underfill. This "void" will be either a vacuum or will contain air or other vapour produced by outgassing of the surrounding materials. It is the total reflection occurring at the interface between the chip underside and this void material that produces the strong signal in the SAM images. Sound wave transmission across an interface at which there is intimate contact between the die and the underfill, despite the absence of strong chemical bonding, is enough to produce a SAM image that does not show delamination. This is demonstrated by the images obtained before thermal cycling treatment of the die. For the die on board 1, the poor accuracy of the flux application before die placement and reflow may have provided a reservoir of material to outgas during the thermal cycling process. This gas could then create a void between chip and underfill leading to a strong reflection in the SAM image. For the die assembled onto board 2, the more accurate fluxing of only the solder balls led to far less residue being left behind in the assembly before underfill application.

\section{Conclusion}

In this paper we have demonstrated the use of low surface energy coatings to control the adhesion between the die surface and conventional underfill materials in flip-chip assemblies. These experiments have shown that it is possible to substantially reduce the adhesion of the underfill to the die surface by applying a self-assembled monolayer of octadecyltrichlorosilane (OTS) to the die before reflow and underfill application. The non-adhesion of the underfill to the die surface leads to early electrical failure of the devices. In this work, scanning acoustic microscopy has been used to monitor the delamination of the die with the surprising result that despite the almost complete nonadhesion of the die to the underfill, in certain circumstances no delamination is observable. This may be significant in that SAM has been used as an indication of the quality of device assembly, including underfill - die interface integrity, but is clearly not always able to indicate substantial regions of poor adhesion. 


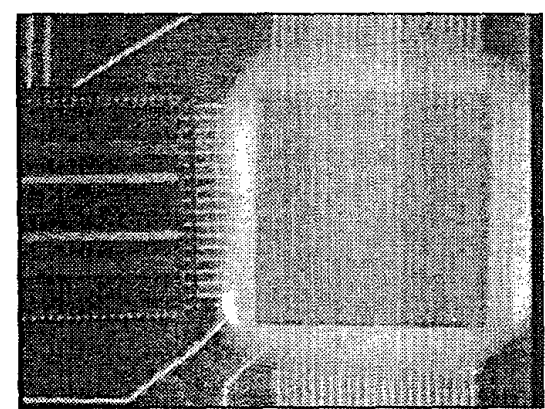

Figure 7: Underside of chip and indentation in underfill left behind after removal of die from site 1 .

\section{References}

1. Katsurayama, S. and Wada, M., "Development of Underfill Material with High Valued Performance", Advances in Electronic Packaging EEP-Vol. 26-1 (1999) pp. 391- 396.

2. Vincent, M.B., and Wong, C.P., "Enhancement of Underfill Encapsulants for Flip-chip Technology", Soldering and Surface Mount Technology, vol. 11 (1999) pp. 33-39.

3. Hutt, D.A., Mannan, S.H., Whalley, D.C., Conway, P.P., "A Maskless, Low Cost Multi-Chip-Module Assembly Process", Advances in Electronic Packaging, EEP-Vol. 26-2 (1999) pp. 1705-1711.

4. Tsukruk, V.V. and Bliznyuk, V.N., "Adhesive and Friction Forces between Chemically Modified Silicon and Silicon Nitride Surfaces", Langmuir vol. 14, (1998) pp. 446-455.

5. Ulman, A., "An Introduction to Ultrathin Organic Films”, Academic Press, Inc., Boston (1991).

6. Sigmund, J., Goings, J. and Kearney, M.A., "Tomographic Acoustic Micro-imaging (TAMI) Improves Acoustical Analysis of Flip-chip Packages", Advances in Electronic Packaging EEP-Vol. 26-1 (1999) pp. 855-857.

7. Hanna, C.E. and Sitaraman, S.K., "Role of Underfill Materials and Thermal Cycling on Die Stresses", Advances in Electronic Packaging EEP-Vol. 26-1 (1999) pp. 795-802.

8. Wheeler, D. and Bailey, C., unpublished work (1999).

\section{Acknowledgments}

The authors would like to acknowledge the support of the British Council (grant no. 9050129) for this work, which enabled the exchange of researchers between the two institutions. In addition, the support provided to Loughborough University by the EPSRC (grant no. GRL61767) is gratefully acknowledged, together with the assistance provided by the following industrial partners: Celestica Ltd., Multicore Solders, Matra BAe, Intarsia Corporation, DEK Printing Machines and Mitel Semiconductors.

\section{Biographies}

David Hutt received his BSc degree in Chemistry in 1988 , and $\mathrm{PhD}$ in Physical Chemistry in 1991 from Imperial College, University of London, UK. He subsequently carried out research at a number of UK Universities, working predominantly in the field of surface chemistry and surface analysis. Dr. Hutt has authored over 20 scientific and technical journal papers. Since 1997, as a research associate and more recently as a lecturer at Loughborough University, UK, he has been investigating novel methods for low-cost flip-chip assembly.

Patrick Webb received his B.Sc. in Mathematical Physics from UMIST in 1988. His M.Sc. and Ph.D. were in the area of amorphous electronic materials, received respectively from Dundee University in 1990 and the University of Abertay Dundee in 1995. Dr Webb then joined the Electronic Engineering department of the City University of Hong Kong, initially working on amorphous and organic electronic materials, and later in the field of electronic packaging. He is now a member of the PRIME Faraday programme at Loughborough University. His current interests are low cost flip chip assembly and fabrication of large area flexible printed circuits.

K.C. Hung received the B.Sc. degree in Applied Physics from the City Polytechnic of Hong Kong in 1993 and the Ph.D. degree in Physics and Materials Science from the City University of Hong Kong in 1998. He currently works in the Department of Electronic Engineering, City University of Hong Kong as a Research Fellow. He has authored or co-authored over 30 technical publications in refereed journals. His current research interests include the advanced electronics packaging technology, reliability engineering, failure analysis and nondestructive testing.

C. W. Tang received the B.Sc. degree in mechanical engineering (first class honors) and M.Sc. (Eng) degree (distinction) from the University of Hong Kong, and is currently pursuing the $\mathrm{Ph} . \mathrm{D}$. degree in advanced packaging of flip chip assemblies in City University of Hong Kong. His research interests are in advanced electronics manufacturing technology and reliability issues of no-flow underfill and anisotropic conductive film (ACF) of flip chip assemblies.

Paul Conway graduated from the University of Ulster in 1988 with First Class Honours and later continued his education at Loughborough, graduating with an MSc in 1989. He is currently a Reader at Loughborough University in the Department of Manufacturing Engineering. He has previously worked as a Research Assistant on a project addressing process modelling of reflow soldering and prior to that as an Industrial Engineer with Fisher Body Overseas Corp., General Motors Corp. He has held a number of substantial UK, European and industrially funded research projects and has published widely in the field of electronics manufacturing and micro-systems technology. 
David Whalley graduated from Loughborough University in 1984. Since then he has been involved in research into electronic interconnection reliability, new interconnection technologies such as conductive adhesives and into the use of engineering analysis techniques both in electronic product design and for electronic manufacturing process simulation. He has worked as a research engineer both at Loughborough University and at the Lucas Advanced Engineering Centre in Solihull, Birmingham and he is currently a Senior Lecturer in Loughborough University's Department of Manufacturing Engineering.

Y. C. Chan earned a B.Sc. degree in Electrical Engineering in 1977, a M.Sc. degree in Materials Science in 1978, and a Ph.D. Degree in Electrical Engineering in 1983, all from Imperial College, University of London. He has worked at Fairchild Semiconductor as a Senior Engineer, as a Lecturer in Electronics at the Chinese University of Hong Kong and at SAE Magnetics (HK) Ltd. and Seagate Technology. He joined the City Polytechnic of Hong Kong (now City University of Hong Kong) as a Senior Lecturer in Electronic Engineering in 1991. He is currently Professor in the Department of Electronic Engineering and Director of the EPA Centre. His current technical interests include advanced electronics packaging and assemblies, failure analysis, and reliability engineering. 